\title{
PENGARUH MODEL COOPERATIVE LEARNING TIPE JIGSAW TERHADAP HASIL BELAJAR BOLA BASKET
}

\author{
Zulkifli Lamusu, Syarifudin \\ Universitas Negeri Gorontalo \\ zulkiflilamusu@gmail.com
}

Received: 29 Februari 2019; Revised: 12 April 2019; Accepted: 15 April 2019

\begin{abstract}
ABSTRAK
Metode penelitian yang digunakan adalah metode Penelitian eksperimen. Dengan desain terdiri atas 2 variabel penelitian yaituVariabel $\mathrm{X}$ (Model Cooperative Learning tipe Jigsaw) denganVariabel Y (HasilBelajarSiswa), dengan prosedur penelitian "Pre Test $\left(\mathrm{X}_{1}\right)$,Treatmen $(\mathrm{T})$, dan Post Test $\left(\mathrm{X}_{2}\right)$. Populasi dalam penelitian adalah seluruh siswa kelas VII-1 SMP Negeri 1 Telaga Biru yang berjumlah 26 siswa. Adapun sampel dalam penelitian yang ditetapkan adalah keseluruhan dari populasi sebanyak 26 siswa Kelas VII-1 yang diambil secara Total Sampling. Uji statistik yang digunakan untuk menguji hipotesis penelitian ini adalah Uji $t$, dan berdasarkan hasil analisis diperoleh harga $t_{\text {hitung }}$ sebesar 31,77 , Sedangkan dari daftar distribusi $t$ pada taraf nyata $1 \%$ diperoleh harga $\mathrm{t}_{\text {daftar }}$ atau $\mathrm{t}_{(0,995(25)}=2,79$. Ternyata harga $t_{\text {hitung }}$ telah berada di dalam daerah penerimaan $\mathrm{H}_{\mathrm{A}}$ atau diluar penerimaan $H_{0}$.

Kata Kunci: Model Cooperative LearningTipe Jigsaw, HasilBelajarBola Basket.
\end{abstract}

\section{PENDAHULUAN}

Undang-Undang No. 20 Tahun 2003 tentang Sistem Pendidikan Nasional meyatakan bahwa pendidikan adalah usaha sadar dan terencana untuk mewujudkan suasana belajar dan proses pembelajaran agar peserta didik secara aktif mengembangkan potensi dirinya untuk mewakili kekuatan spiritual keagamaan, pengendalian diri, kepribadian, kecerdasan, ahlak mulia serta keterampilan yang diperlukan dirinya, masyarakat, bangsa, dan negara.(wina sanjaya, $2009: 2$ )

Upaya untuk mengembangkan potensi anak dalam permainan bola basket dapat dilakukan melalui pendidikan jasmani disekolah, juga dapat melalui kegiatan olehraga pilihan yang diterapkan di sekolah- sekolah.Bola basket yang diterapkan dalam pendidikan jasmani harus dapat diarahkan dengan baik, serta dibimbing dengan baik agar dapat bermanfaat dalam usaha menwujudkan tercaipannya tujuan pendidikan. Sebab didalam pelaksanaan permainan bola basket sangat erat kaitannya denganh kesan pribadi yang menyenangkan bagi anak didik, sehingga anak akan dapat mengemukakan ungkapan-ungkapan kreatifnya meningkatkan keterampilan gerak dan kebugaran jasmaninya.

Hasil obserpasi dalam penelitian hasil belajar yang dilakukan akan dilaksanakan sesuai dengan Kurikulum yang berlangsung disekolah tersebut. Dalam mata pelajaran Pernjasorkes kelas VII-2 khususnya cabang olahraga bola basket, materi yang diajarkan disekolah adalah teknik dasar Operan (pasing).

Untuk dapat bermain bola basket, diperlukan penguasan gerak dasar permainan bola basket itu sendiri. Salah satu teknik dasar permainan bola basket yang 
dilakukan oleh siswa dalam penelitian adalah operan (passing) bola. Pelaksanaan operan pada permainan bola basket dapat dilakukan dengan berbagai cara. Jenisjenis operan yang dilakukan pada permainan bola basket yaitu operan dada, operan bola dari atas kepala, dan lemparan pantulan.Untuk mengembangkan kemampuan operan dapat dilakukan dengan berbagai strategi, dan model pembelajaran yang efektif dalam penjasorkes.

Masalah ini sangat berdekatan dengan tugas pokok guru pendidikan jasmani dalam mendidik, mengajar dan melatih siswa agar mereka dapat mencapai hasil belajar yang lebih optimal. Agar guru pendidikan jasmani efektif dalam melaksanakan tugasnya, maka guru harus berupaya mencari dan mencoba dan menerapkan metode pembelajaran yang relevan dengan bentuk-bentuk gerak yang berdasar pada tahap-tahap perkembangan karakteristik siswa.

Sehubungan dengan ini, menurut pengamatan penulis bahwa kelemahan dalam pendidikan jasmani di SMP NEGERI 1 TELAGA BIRU umumnya terdapat pada penggunaan model pembelajaran yang kurang tepat dalam penelitian model seperti yang dimaksudkan diatas mengakibatkan tugas gerak yang diberikan kepada siswa tidak berdampak positif terhadap pengembangan dan penguasaan keterampilan teknik-teknikdasar pada permainan bola basket.

Sehubungan hal tersebut diatas, kenyataan yang ada dalam proses pembelajaran bola basket di SMP NEGERI 1 TELAGA BIRU, teknik dasar pada permainan bola basket oleh para siswa masih mengalami kesulitan dalam melakukannya, yang akhirnya secara menyeluruh hasil belajar siswa kurang maksimal. Hal ini terjadi karena kurangnya pemahaman bagi sebagian guru pendidikan jasmani akan pentingnnya penerapan modelpembelajaran yang relevan dengan karakteristik siswa, sehingga siswa kurang memahami dan bersungguh-sungguh dalam menerima pelejaran.

Mengingat kondisi di atas, maka model yang mungkin tepat diterapkan dalam pembelajaran bola basket terkait dengan hasil belajar siswa dalam bermain bola basket adalah model Kooperative Learning. Melalui Pembelajaran Kooperatif para siswa akan belajar dalam kelompok. Keberadaannya di dalam kelompok akan membuat mereka lebih bersemangat dalam belajar dan dengan keberadaannya di dalam kelompok itu pula akan lebih memberikan pengalaman yang berarti akan perlunya kerja sama.

\section{TINJAUAN PUSTAKA}

\section{Hakikat Model Pembelajaran}

Model pembelajaran merupakan landasan praktik pembelajaran hasil penurunan teori psikologi pendidikan dan teori belajar yang di rancang berdasarkan analisis terhadap implementasi kurikulum dan implikasinya pada tingkat operasional di kelas. Model pembelajaran dapat di artikan pula sebagai pola yang digunakan untuk menyusun kurikulum, mengatur materi, dan memberi petunjuk pada guru di kelas. Model pembelajaran ialah pola yang digunakan sebagai pedoman dalam merencanakan pembelajaran di kelas.Model pembelajaran mengacu pada pendekatan yang digunakan, termasuk di dalamnya tujuan-tujuan pembelajaran, tahap-tahap dalam kegiatan pembelajaran, lingkungan pembelajaran, dan pengelolaan kelas. Suprijono (2011:46) mengatakan bahwa model pembelajaran dapat didefinisikan sebagai kerangka konseptual yang melukiskan 
prosedur sistematis dalam mengorganisasikan pengalaman belajar untuk mencapai tujuan belajar.

Mills berpendapat dalam buku Suprijono,( 2011 :45) bahwa "model adalah bentuk representasi akurat sebagai proses aktual yang memungkinkan seseoarang atau sekelompok orang mencoba bertindak berdasarkan model itu". Model merupakan interprestasi terhadap hasil observasi dan pengukuran yang diperoleh dari beberapa sistem. (Suprijono, 2011: 45).

Model pembelajaran ialah pola yang digunakan sebagai pedoman dalam merencanakan pembelajaran dikelas maupun tutorial. Menurut Arends, model pembelajaran mengacu pada pendekatan yngakan digunakan, pada pendekatan yang akan digunakan, termasuk didalamnya, tujua-tujuan pembelajaran, tahaptahap dalam kegiatan pembelajaran, lingkungan pembelajaran, dan pengelolahan kelas. Model pembelajaran dapat didefinisikansebagai kerangka konseptual yang melukiskan prosedur sistematis dalam mengorganisasikan pengalaman belajaruntuk mencapai tujuan belajar. (Suprijono, 2011: 46)

Dengan demikian melalui model pembelajaran dapat membantu peserta didik untuk mendapatkan informasi, ide, keterampilan, cara berpikir, dan mengekspresikan ide. Model pembelajaran berfungsi pula sebagai pedoman bagi para perancang pembelajaran danpara guru dalam merencanakan aktifitas belajar mengajar.

\section{Model Pembelajaran dalam Penjasorkes}

Pendidikan jasmani pada dasarnya merupakam pendidikan melalui aktivitas jasmani yang dijadikan sebagai media untuk mencapai perkembangan individu secara menyeluruh. Namun perolehan keterampilan dan perkembangan lain yang berisi jasmani itu juga sekaligus sebagai tujuan. Melalui pendidikan jasmani, siswa disosialisasikan kedalam aktivitas jasmani termasuk keterampilan berolahraga. Oleh karena itu tidaklah mengherankan apa bila banyak yang meyakini dan mengatakan bahwa pendidikan jasmani merupakan bagian dari pendidikan menyeluruh dan sekaligus memiliki potensi yang strategis untuk mendidik.

Dengan perkataan lain pendidikan jasmani berusaha untuk mengembangkan pribadi secara keseluruhan dengan sarana jasmani yang merupakan saham, khususnya yang tidak diperoleh dari usaha-usaha pendidikan yang lain karena hasil pendidikan dari pengalaman jasmani tidak terbatas pada perkembangan tubuh atau fisik. Pendidikan jasmani berkewajiban meningkatkan jiwa dan raga yang mempengaruhi semua aspek kehidupan sehari-hari seseorang atau keseluruhan pribadi seseorang. Pendidikan jasmani menggunakan pendekatan keseluruhan yang mencakup semua kawasan baik organik, motorik, kognitif, maupun afektif, karena manusia dipandang seutuhnya. Pelajaran penjas merupakan salah satu mata pelajaran dari sekolah yang mulai diajarkan pada sekolah dasar sampai sekolah menengah umum bahkan sampai ke perguruan tinggi.

Disekolah dasar pelajaran penjas belum diajarkan secara khusus, tetapi secara tidak langsung mereka telah mengenal dan mempelajari ilmu penjas. Bagi siswa sekolah menengah umum mungkin pelajaran penjas sudah tidak asing lagi karena mereka telah memperoleh pengetahuan dasar tentang pelajaran penjas dengan baik, maka tidak sedikit diantara mereka yang merasakan bahwa pelajaran 
http : //ejurnal.pps.ung.ac.id/index.php/AKSARA/index

penjas sulit dipahami, sehingga dengan demikian siswa mau melakukan dan mempelajari pelajaran penjas.

Model Keterpaduan keterampilan dan kesegaran jasmani adalah model yang mengkondisikan komponen kesegaran jasmani dan keterampilan yang menyatuh dalam aktivitas bermain.

Keuntungan menggunakan MK3 antara lain:

1. Menanamkan kesadaran tentang manfaat jasmani bagi siswa

2. Menanamkan kegemaran mengikuti aktivitas jasmani secara teratur, terarah dan terseleksi

3. Menumbuhkan budaya hidup aktif melalui aktivitas jasmani

4. Mengembangkan keterampilan motori dan kesegaran jasmani melalui aktivitas jasmani yang terarah

5. Terjadinya perubahan pandangan yang positif terhadap aktivitas jasmani bagi dirinyadan lingkungan

Menurut Tomiliyus, Model pembelajaran Penjas Konsep MK3 sebagai berikut :

\section{$\underline{\text { KONSEP MK3 }}$}

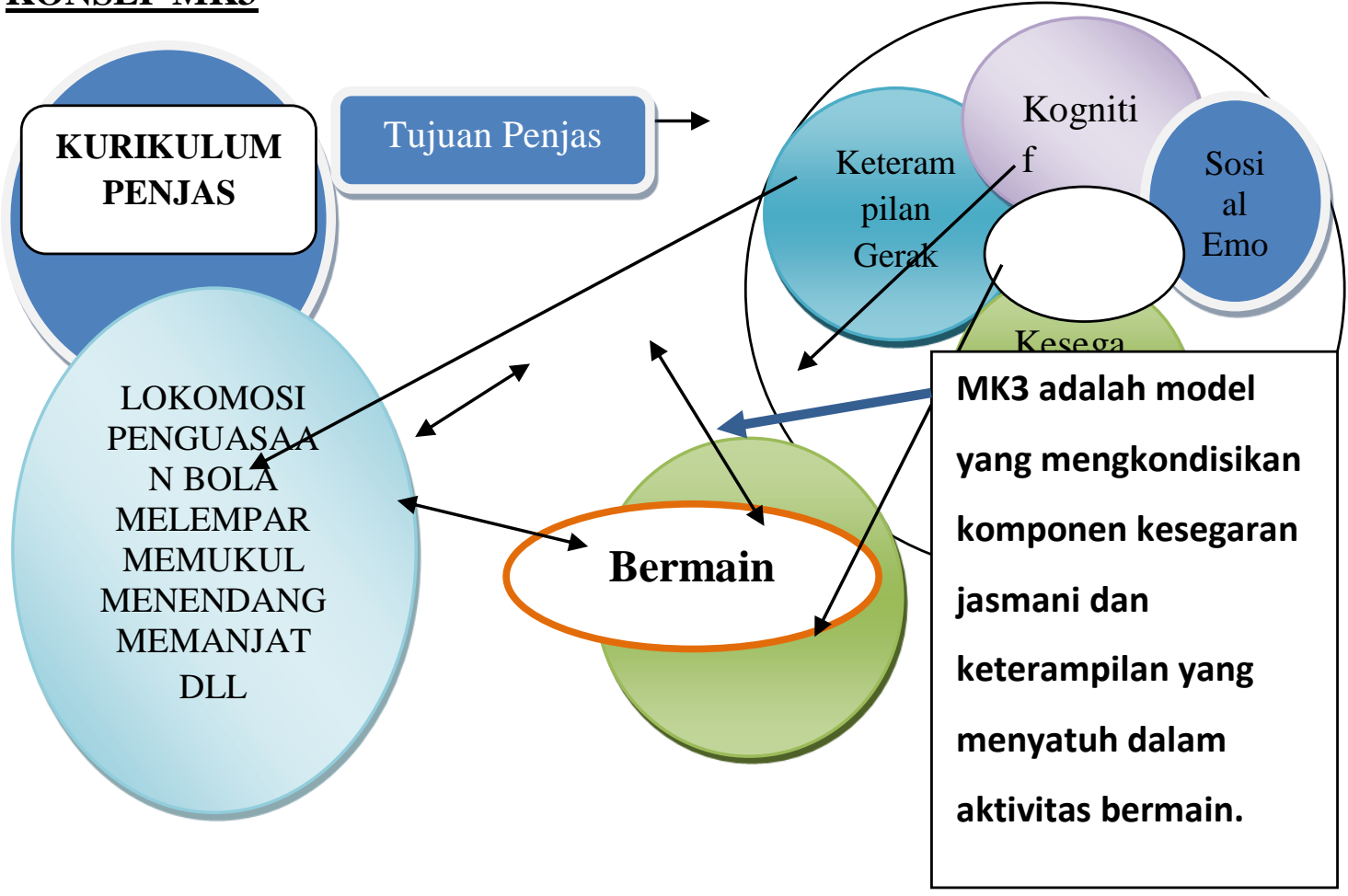

Tomoliyus,

http://www.google.co.id=j\&q=tomoliyus-ms\%2Fmodelpembelajaran-penjas.pdf, Akses 22 April 2013

Model Pengembangan Penalaran Melalui Permainan adalah model yang menekankan peningkatan kemampuan memecahkan masalah, kreativitas, kerjasama kelompok dan persepsi motorik melalui permainan.

Konsep MP3 sebagai berikut:

\section{KONSEP MP3 / PENDEKATAN TAKTIS}

132 AKSARA Jurnal Ilmu Pendidikan Nonformal 


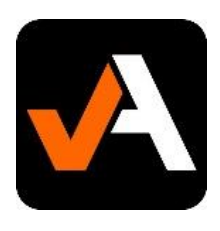

http : //ejurnal.pps.ung.ac.id/index.php/AKSARA/index

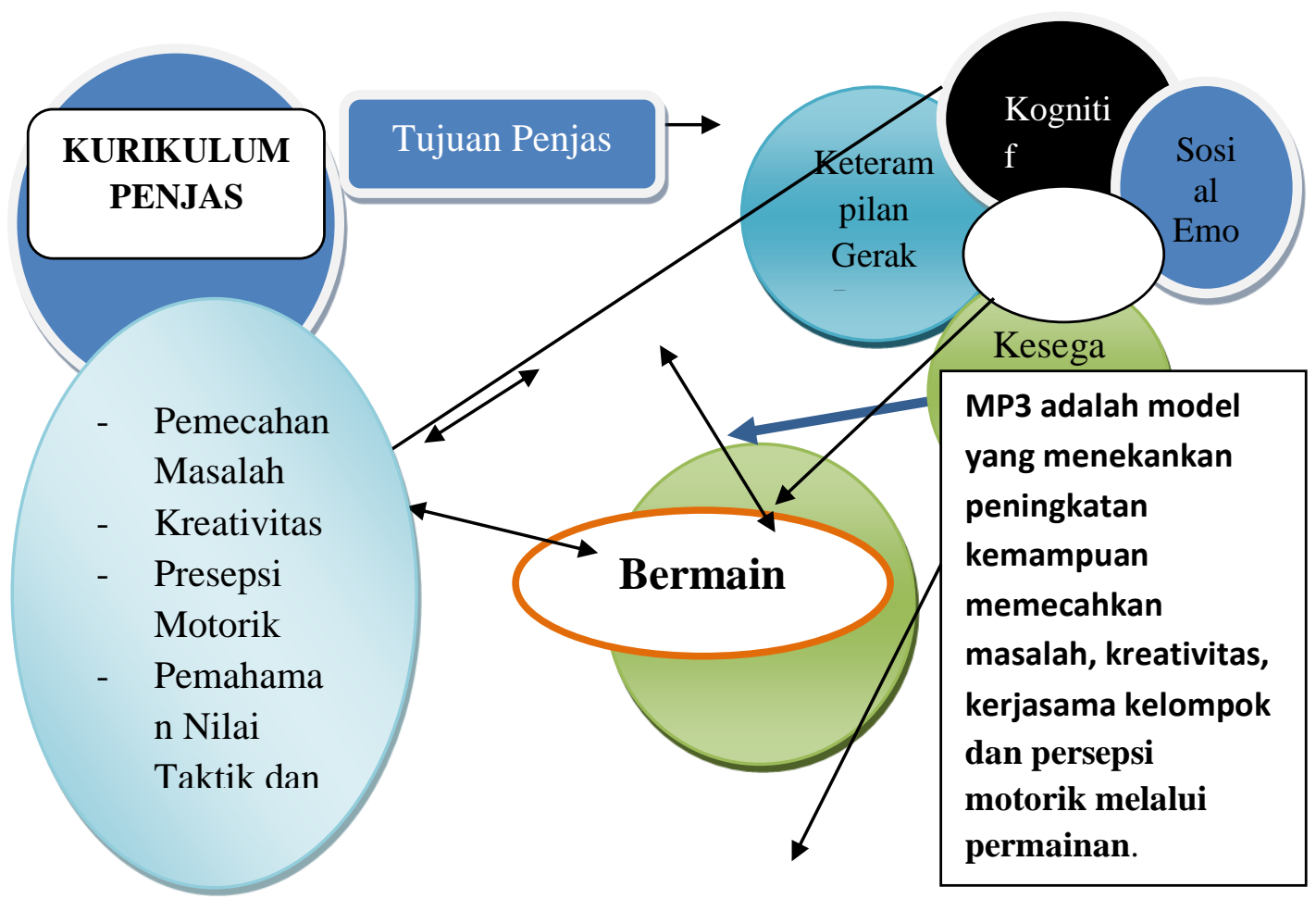

Tomoliyus,

http://www.google.co.id=j\&q=tomoliyus-ms\%2Fmodelpembelajaran-penjas.pdf, Akses 22 April 2013

Keuntungan menggunakan MP3 / Pendekatan Taktis

1. Membudayakan perilaku normatif dan memiliki rasa tanggung jawab terhadap tugasnya

2. Membudayakan kebiasaan menerima perbedaan di antara anggota kelompok, menghargai kelmpok maupun kelompok lain, terutama dalam keterampilan jasmani

3. Memberi pemahaman kepada siswa bahwa aktivitas jasmani termasuk permainan menyediakan kesempatan untuk mendapatkan kegembiraan, tantangan dan ekspresi pribadi dalam interksi

4. Memberi kesempatan kepada anak untuk memahami konsep permainan, termasuk taktik dan strategi, peraturan permainan serta prinsip-prinsip dan nilai-nilai yang terkandung dalam permainan

5. Mengembangkan kreativitas dan penalaran siswa

6. Meningkatkan kemampuan siswa dalam memecahkan masalah

7. Memberi kesempatan kepada anak untuk berinteraksi berbagai pengalaman dan kerja sama.

Dengan berdasarkan pemikiran di atas maka prestasi belajar penjas perlu adanya penataan dari berbagai segi antara lain dalam kaitannya dengan pengetahuan dasar siswa, cara belajar siswa dan juga kesiapan yang bersangkutan sebelum mengikuti suatu pelajaran. Dunia pendidikan tidak akan berkembang tanpa memperbaiki proses belajar mengajar yang mampu mengembangkan tanpa memperbaiki proses belajar mengajar yang mampu mengembangkan daya kreativitas dan aktivitas siswa, sehingga memperolehhasil yang maksimal. 


\section{Kooperative Learning}

Pembelajaran kooperatif merupakan salah satu model pembelajaran kelompok yang memiliki aturan tertentu.Prinsip dasar dasar pembelajaran kooperatif adalah siswa membentuk kelompok kecil dan saling mengajar sesamanya untuk mencapai tujuan bersama.Dalam pembelajaran kooperatif siswa pandai mengajar siswa yang kurang pandai tanpa merasa dirugikan.Siswa kurang pandai dapat belajar dalam suasana yang menyenangkan karena banyak teman yang membantu dan memotivasinya. Siswa yang sebelumnya terbiasa bersikap pasif setelah menggunakan pembelajaran kooperatif akan terpaksa berpartisipasi secara aktif agar bisa diterima oleh anggota kelompoknya.(Priyanto,2007 dalam Wena, 2010:189).

Melalui pembelajaran kooperatif akan member kesempatan pada siswa untuk bekerja sama dengan sesama siswa dalam tugas-tugas yang berstruktur. Melalui pembelajaran koperatif pula, seorang siswa akan menjadi sumber belajar bagi temannya yang lain. Lie (2002) mengatakan bahwa pembelajaran kooperatif dikembangkan dengan dasar asumsi bahwa proses proses belajar akan lebih bermakna jika peserta didik dapat saling mengajari. Walaupun dalam pembelajaran kooperatif siswa dapat belajar dari dua sumber belajar utama, yaitu pengajar dan teman belajar lain. (Wena, 2010:189).

Pembelajaran kooperatif adalah pembelajaran yang secara sadar menciptakan interaksi yang silih asah sehingga sumber belajar bagi siswa bukan hanya guru dan buku ajar, tetapi juga sesama siswa (Nurhadi dan Senduk, 2003). Menurut Lie (2002) pembelajaran kooperatif adalah system pembelajaran yang member kesempatan kepada siswa bekerja sama dengan sesama siswa dalam tugas-tugas terstruktur, dan dalam system ini guru bertindak sebagai fasilitator. (Wena, 2010:189:190).

pembelajaran kooperatif adalah konsep yang lebih luas meliputi semua jenis kerja kelompok termasuk bentuk-bentuk yang lebih dipimpin oleh guru atau diarahkan guru. Secara umum pembelajaran kooperatif dianggap lebih diarahkan oleh guru, dimana guru menetapkan tugas dan pertanyaan-pertanyaan serta menyediakan bahan-bahan dan informasi yang dirancang untuk membantu peserta didik menyelesaikan masalah yang dimaksud. Guru biasanya menetapkan bentuk ujian tertentu pada akhir tugas.

\section{METODE PENELITIAN}

Metodologi mengandung makna yang lebih luas menyangkut prosedur dan cara melakukan verifikasi data yang diperlukan untuk memecahkan masalah penelitian termasuk untuk menguji hipotesis (Sudjana dan Ibrahim 2010 : 16). Penelitian ini menggunakan metode eksperimen yaitu penelitian terdiri atas 2 (dua) variable yaitu variable X (Cooperative Learning) dan variable Y (Hasil BelajarBola Basket).

Desain penelitian yang digunakan oleh peneliti adalah Pre Test dan post test dengan desain atau rancangan sebagai berikut.

Tabel 1. Rancangan Desain Penelitian

\begin{tabular}{|l|l|l|}
\hline Pretest & Treatmen & Posttest \\
\hline$X_{1}$ & $\mathrm{~T}$ & $X_{2}$ \\
\hline
\end{tabular}


http : //ejurnal.pps.ung.ac.id/index.php/AKSARA/index

Keterangan:

X1 : Hasil kemampuan sebelum di terapkan Model pembelajaran

$\mathrm{T} \quad$ : Treatmen (perlakuan berupa penerapan model pembelajaran)

X2 : Hasil belajar setelah diterapkan model pembelajaran

Untuk hasil belajar bola basket, instrumen ini meliputi tes passing Bola Basket berdasarkan pokok bahasan materi pembelajaran pendidikan jasmani, olahraga dan kesehatan kelas VIISMP N 1 Telaga Biru, tes tersebut yaitu: tes Operan (passing) dalam permainan bola basket

Untuk memperoleh data yang dibutuhkan dalam penelitian ini, maka peneliti melakukan pengamatan langsung terhadap obyek yang di teliti. Selanjutnya peneliti melakukan pengukuran terhadap:

1. Siswa secara umum diberikan tes awal (pre test) untuk mengetahui tingkat kemampuan teknik passing dalam permainan bola basket dengan cara masingmasing siswa melakukan teknik dasar passing (chest pass, bouce pass, operhead pass)secara berpasangan..

2. Setelah mengetahui tingkat kemampuan awal para siswa, selanjutnya siswa diberikan perlakuan berupa penerapan model cooperative learning tipe Jigsaw dengan jumlah siswa 26 orang dibentuk dalam kelompok yang masing-masing kelompok sebanyak 3-5 orang siswa.

3. Data yang diambil pada tes akhir adalah hasil belajar setalah diterapkan model pembelajaran kooperatif tipe jigsaw ( perlakuan ) yang dinilai secara indvidu pada teknik dasar passing.

4. Pengambilan data tes awal dan tes akhir pada teknik dasar dalam passing (chest pass, bouce pass, operhead pass) yang dinilai dalam format penilaian Rating scale.

\section{HASIL PENELITIAN DAN PEMBAHASAN}

Skor data variabel $\mathrm{X}_{1}$ dalam penelitian ini adalah skor data yang dijaring sebelum pelaksanaan adanya tindakan pada siswa yang menjadi sampel terhadap keterampilan melakukan teknik dasar passing dalam permainan bola basket. Dari data yang diperoleh menunjukkan skor tertinggi2,63dan skor yang terendah 2,18. Setelah dilakukan analisis diperoleh nilai rata-rata 2,40 dan nilai varians sebesar 0.013 serta standar deviasi sebesar0.11. Distribusi frekuensi data variabel $\mathrm{X}_{1}$ dapat dilihat pada tabel berikut:

\begin{tabular}{|l|l|}
\hline NO & SCORE Pre-test \\
\hline 1. & $\mathbf{2 , 6 3}$ \\
\hline 2. & $\mathbf{2 , 5 4}$ \\
\hline 3. & $\mathbf{2 , 4 5}$ \\
\hline 4. & $\mathbf{2 , 5 4}$ \\
\hline 5. & $\mathbf{2 , 5 4}$ \\
\hline 6. & $\mathbf{2 , 3 6}$ \\
\hline 7. & $\mathbf{2 , 3 6}$ \\
\hline 8. & $\mathbf{2 , 5 4}$ \\
\hline 9. & $\mathbf{2 , 5 4}$ \\
\hline 10. & $\mathbf{2 , 3 6}$ \\
\hline
\end{tabular}


http : //ejurnal.pps.ung.ac.id/index.php/AKSARA/index

\begin{tabular}{|l|l|}
\hline 11. & $\mathbf{2 , 5 4}$ \\
\hline 12. & $\mathbf{2 , 2 7}$ \\
\hline 13. & $\mathbf{2 , 3 6}$ \\
\hline 14. & $\mathbf{2 , 2 7}$ \\
\hline 15. & $\mathbf{2 , 2 7}$ \\
\hline 16. & $\mathbf{2 , 2 7}$ \\
\hline 17. & $\mathbf{2 , 2 7}$ \\
\hline 18. & $\mathbf{2 , 4 5}$ \\
\hline 19. & $\mathbf{2 , 3 6}$ \\
\hline 20. & $\mathbf{2 , 4 5}$ \\
\hline 21. & $\mathbf{2 , 3 6}$ \\
\hline 22. & $\mathbf{2 , 3 6}$ \\
\hline 23. & $\mathbf{2 , 3 6}$ \\
\hline 24 & $\mathbf{2 , 3 6}$ \\
\hline 25 & $\mathbf{2 , 4 5}$ \\
\hline 26 & $\mathbf{2 , 1 8}$ \\
\hline JUMLA & $\mathbf{6 2 , 4 4}$ \\
H & \\
\hline \hline
\end{tabular}

Tabel 4.2

\section{Daftar Distribusi Frekuensi Variabel $\mathrm{X}_{1}$}

Berdasarkan tabel distribusi frekuensi di atas, maka dapat digambarkan bahwa setiap siswa memiliki skor yang tidak jauh berbeda. Untuk memperjelas lagi dapat di lihat dalam diagram berikut :

\section{Gambar 4.1. Diagram Pre-test}

Dalam diagram batang ini, tampak terlihat skor pre-test yang memang tidak jauh berbeda. Scor terendah adalah 2,18 sedangkan scor tertinggi adalah 2,63.

\section{SCORE Pre-test}

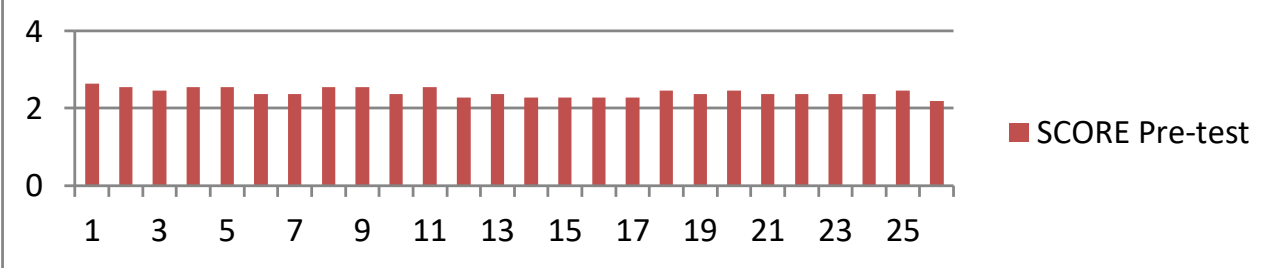

Deskripsi Hasil Penelitian Variabel $\mathrm{X}_{2}$ (Hasil Tes Akhir Keterampilan teknik dasar passing dalam permainan Bola Basket)

Skor data variabel $\mathrm{X}_{2}$ adalah skor data yang dijaring setelah pelaksanaan eksperimen terhadap kemampuan passing dalam permainan Bola Basket. Dari data yang diperoleh menunjukkan skor tertinggi 4.09 dan skor terendah 3.18. Setelah dilakukan analisis diperoleh skor rata-rata 3,51 sedangkan nilai varians sebesar 0,039 dan niai standar deviasi sebesar0,19. Distibusi frekuensi data variabel $X_{.2}$ dapat dilihat pada tabel berikut:

\begin{tabular}{|l|l|}
\hline NO & SCORE Post-test \\
\hline 1. & $\mathbf{3 , 7 2}$ \\
\hline
\end{tabular}


http : //ejurnal.pps.ung.ac.id/index.php/AKSARA/index

\begin{tabular}{|l|l|}
\hline 2. & $\mathbf{3 , 5 4}$ \\
\hline 3. & $\mathbf{3 , 5 4}$ \\
\hline 4. & $\mathbf{3 , 8 1}$ \\
\hline 5. & $\mathbf{3 , 5 4}$ \\
\hline 6. & $\mathbf{3 , 3 6}$ \\
\hline 7. & $\mathbf{3 , 5 4}$ \\
\hline 8. & $\mathbf{3 , 5 4}$ \\
\hline 9. & $\mathbf{3 , 5 4}$ \\
\hline 10. & $\mathbf{3 , 3 6}$ \\
\hline 11. & $\mathbf{3 , 3 6}$ \\
\hline 12. & $\mathbf{3 , 2 7}$ \\
\hline 13. & $\mathbf{3 , 1 8}$ \\
\hline 14. & $\mathbf{3 , 4 5}$ \\
\hline 15. & $\mathbf{3 , 3 6}$ \\
\hline 16. & $\mathbf{3 , 1 8}$ \\
\hline 17. & $\mathbf{3 , 4 5}$ \\
\hline 18. & $\mathbf{3 , 6 7}$ \\
\hline 19. & $\mathbf{3 , 4 5}$ \\
\hline 20. & $\mathbf{4 , 0 9}$ \\
\hline 21. & $\mathbf{3 , 5 4}$ \\
\hline 22. & $\mathbf{3 , 5 4}$ \\
\hline 23. & $\mathbf{3 , 4 5}$ \\
\hline 24 & $\mathbf{3 , 8 1}$ \\
\hline 25 & $\mathbf{3 , 4 5}$ \\
\hline 26 & $\mathbf{3 , 4 5}$ \\
\hline JUMLA & $\mathbf{9 1 , 1 9}$ \\
\hline H & \\
\hline
\end{tabular}

Tabel 4.3. Daftar Distribusi Frekuensi Variabel $X_{2}$

Tabel diatas menunjukan hasil post-test dalam penelitian ini, untuk lebih jelasnya data dalam tabel diatas dapat dilihat pada diagram berikut :

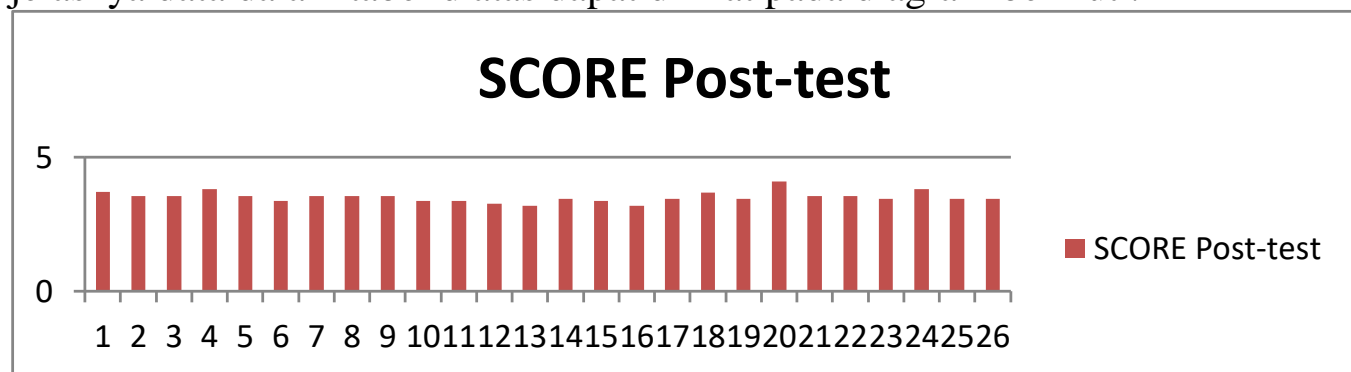

\section{Gambar 4.2. Diagram Post-test}

Jika dalam diagram sebelumnya, yaitu pada hasil pre-test yang hasil tes tertingginya adalah 2,36 dan terendah adalah 2,18. Maka dalam diagram ini terlihat mengalami peningkatan . terbukti dalam diagram ini tampak scor tertinggi adalah 4,09 sedangkan scor terendah adalah 3,18.

\section{PENUTUP}


Berdasarkan hasil penelitian menunjukkan bahwa ada pengaruh yang signifikan antara siswa yang diajar dengan menggunakan Model Cooperative Learning Tipe Jigsaw dan siswa yang diajar tanpa menggunakan Model Cooperative Learning Tipe Jigsaw pada siswa kelas VII-1 SMP Negeri 1 Telaga Biru. Dengan demikian pembelajaran dengan menggunakan Model Cooperative Learning Tipe Jigsaw merupakan salah satu alternatif yang dapat dipilih oleh guru dalam menyampaikan materi pelajaran agar hasil belajar siswa meningkat.

\section{DAFTAR PUSTAKA}

Arikunto, Suharsimi. 2010. Prosedur Penelitian Suatu Pendekatan Praktik. Jakarta : Rineka Cipta

Chandra, Sodikin. 2010. Pendidikan Jasmani Olahraga dan Kesehatan Untuk SMP/MTS Kelas VII. Jakarta : Pusat Perbukuan.

Hadjarati, Hartono. 2011.Bahan Ajar Basket 1.FIKK Universitas Negeri Gorontalo Mohamad Harun, Ronny. 2012.Bahan Ajar Bola Basket 1. FIKK: Universitas Negeri Gorontalo

Samsudi. 2009.Desain Penelitian Pendidikan. Semarang : UNNES PRESS

Sanjaya, Wina. 2009.StrategiPembelajaran Berorientasi Standar Proses Pendidikan.Jakarta : Kencana

Sudjana, Nana.2010. Penilaian Hasil Proses Belajar Mengajar.Bandung : PT Remaja Rosdakarya

Sudjana.Ibrahim. 2010.Penelitian dan Penilaian Pendidikan. Bandung : Sinar Baru Algensindo

Sugiyono. 2010. Metode Penelitian Kuantitatif Kualitatif dan $R \& D$. Bandung : Alfabeta.

Suprijono, Agus. 2011. Cooperative Learning, Teori dan Aplikasi PAIKEM. (Cet.V). Yogyakarta: Pustaka Pelajar.

Tomoliyus, $\quad$ http://www.google.co.id=j\&q=tomoliyus-ms\%2Fmodelpembelajaran-penjas.pdf, Akses 22 April 2013

Wena, Made. 2010. Strategi Pembelajaran Inovatif Kontemporer. Jakarta Timur : PT Bumi Askara

Yunus, Hamzah. 2007.Bahan Ajar Mata Kuliah Statistika Ekonomi. Fakultas Ilmu Sosial : Universitas Negeri Gorontalo 